\title{
Viable Alternatives to Implantology
}

\author{
Zinner ID ${ }^{\star}$, Markovits $\mathrm{S}^{2}$, Miller $\mathrm{RD}^{3}$, Finger $\mathrm{IM}^{4}$, Jansen $\mathrm{CE}^{5}$ and Silberg $\mathrm{SM}^{6}$ \\ ${ }^{1}$ Clinical Professor, Prosthodontics New York University, College of Dentistry \\ ${ }^{2}$ Clinical Professor, Department of Cariology and Comprehensive Care, New York University College of Dentistry \\ ${ }^{3}$ Former Clinical Associate Professor, Prosthodontics New York University, College of Dentistry \\ ${ }^{4}$ Professor, Department of Prosthodontics Louisiana State University School of Dentistry New Orleans, Louisiana \\ Private Practice in Prosthodontics New Orleans, Louisiana \\ ${ }^{5}$ Former Director of Implant Dentistry University of Southern California School of Dentistry Los Angeles, California \\ Private Practice in Prosthodontics Monterey, California \\ ${ }^{6}$ Clinical Associate Professor, C.D.E. American Society of Master Dental Technologists Training Program New York \\ University College of Dentistry
}

${ }^{*}$ Corresponding author: Zinner ID, DDS, MSD, Clinical Professor, Prosthodontics New York University, College of Dentistry, 115 East 61 Street New York, N.Y. 10065, E-mail: idz1@nyu.edu

Citation: Zinner ID, Markovits S, Miller RD, Finger IM, Jansen CE, et al. (2015) Viable Alternatives to Implantology. J Dent Oral Care Med 1(1): 102. doi: 10.15744/2454-3276.1.102

Received Date: February 05, 2015 Accepted Date: May 12, 2015 Published Date: May 14, 2015

\begin{abstract}
In this era of implant dentistry, the teaching and indications for removable prosthodontics is becoming a lost art, especially in affluent urban environments, where most replacements are accomplished by the use of implant fixtures. Removable prosthodontics is still being taught and is used in rural areas and in the elderly patients or medically compromised individual. Therefore it challenges the restorative dentist to be able to fabricate optimum functioning removable complete and partial dentures.

Keywords: Removable prosthodontics; Domestic vs. outsourcing dental laboratory technicians
\end{abstract}

Dental schools especially in affluent urban areas, are currently stressing the use of endosseous implants to replace single teeth, partially edentulous situations, and completely edentulous dental arches. Consequently, there appears to be a lack of teaching of removable prosthodontics. There are dental laboratories usually in urban areas that mostly fabricate implant prosthesis with and without the use of CAD/CAM [1]. Furthermore, there are laboratories that still create fixed and removable partial and complete prostheses for dentists that most probably treat patients in rural areas as well as cities throughout the country that are suffering from high unemployment and therefore we are dealing with monetary concerns. Also, the public is not educated in proper oral systemic health and its importance.

Many people are not candidates for implant procedures. They may have medical and/or psychological problems. They may not have the time or money needed to fabricate implant prostheses. Some of the medical problems that prevent the surgical procedures required include diabetes, carcinoma, and cardiac problems. Psychological problems may prevent many people, especially the elderly, from going through surgery at their advanced age, no less dental implant surgery. Smoking and drug and/or alcohol addiction may also contraindicate the use of implants.

According to the National Board of Certification of Dental Laboratory Technicians, there were 2.8 million complete dentures fabricated in 2013 and 3.7 million removable partial dentures fabricated in 2013. It is projected that there will be 2.9 million complete dentures and 3.9 million removable partial dentures fabricated in 2014. Thus, there is an increase of $2 \%$ of complete dentures made in 2014 over 2013 and 4\% removable partial dentures made in 2014 over 2013 [2].

Thus, this illustrates the need for dental educators, restorative dentists, and our technicians to learn and teach the art and science of removable prosthodontics as well as conventional fixed prosthodontics, since not all edentulous areas are corrected with implant fixtures.

Educational institutions are essential to train technicians in the United States and who will seek employment in the United States. They need teaching in all phases of Prosthodontics, not just implants and cosmetics or ceramics [3]. Since the beginning of outsourcing of laboratory cases to China and elsewhere, there has been a paucity of teaching people to be technicians, getting them a job and then maintaining them. Due to the price differential between American labor and that from abroad, both dentists and laboratory owners have been outsourcing their cases [4]. Thus, in order to avoid this outsourcing the US needs to educate domestic dental technicians [5]. It is possible for any technician to fabricate a removable appliance, but due to the complexity of the art and 
science of removable prosthodontics, the technician and clinician should work as a team for a more favorable prognosis. The creation of a removable appliance requires more art than when fabricating a fixed prosthesis. This is due to the fact that the clinician deals with movable soft tissues and muscles as well as the patient's psychology that is not as predictable as with fixed prosthesis. The fabrication of a conventional fixed appliance involves ceramic full or veneer coverage controlled by the positions of the abutment teeth. Many clinicians do not realize that the fundamental philosophy underlying all prosthodontics, whether it's fixed, removable, or implant supported, is the art and science and the creation of the complete dentures. Esthetics or cosmetics was originally from complete dentures Prosthodontics and the first set of guidelines was published by Dayton Dunbar Campbell from Kansas City, MO in his 1924 text published by CV Mosby Co. of St Louis.

Dental schools, at least in the affluent urban areas, have severely reduced the teaching of complete removable and partial dentures, so much so that the dental students are dependent on a laboratory technician to survey, design and fabricate a removable partial denture. In terms of complete dentures, the future dentists are not learning the basics of the art and science of their fabrication. They are not being taught the anatomy and the stomatognathics that influence complete denture construction, especially the setup of artificial teeth for esthetics and function. This is the basis for the creation of anterior esthetics in all other dental disciplines [6]. Essentially the dentist will be completely dependant upon the technician for case design as well as fabrication of the appliance. When this is the situation, the longevity and comfort as well as esthetics are usually compromised. In terms of fabrication of removable partial dentures, dentists are not taught how to survey a cast for proper design of a clasp retainer, how much relief to use beneath a lingual bar or plate to prevent this major connector from impinging upon the lingual soft tissues [7]. They are also not taught the anatomy of the denture base areas, consequently the bases are either under or over extended. When this occurs, there is a decreased amount of transmission of functional load to the remaining teeth and the denture base. The clinician is now employing CAD/CAM technology in fabrication of removable prosthodontics. Additionally, the practitioner is then dependent upon the technician even if there is a problem with the appliances intra-orally after insertion. The dentist is not being taught how to trouble-shoot removable prosthetic cases. This problem is further exacerbated if the removable appliance is an immediate insertion following extractions. It also extends to the use of tissue conditioners in immediate insertion situations prior to a laboratory rebasing.

The next consideration noted is a limited understanding of the design and use of long term provisional removable prostheses. This is probably one of the most important procedures that the clinician should learn to master. This involves fabrication of a metal substructure and a heat cured acrylic resin superstructure in a removable prostheses. In the removable prostheses, the laboratory fabricates a metal framework to which the artificial teeth and a denture base are fabricated. Following fabrication the dentist is required to be able to fit the prosthesis, adjust the occlusion, and then instruct the patient on how to insert, maintain, and remove the partial denture as well as relearning the masticatory and phonetic skills [5]. The clinician should be taught how to finish and polish the removable appliance in the office prior to insertion.

Future and new dental practitioners are also not being taught the art and science methodology for the construction of partial and complete removable prostheses. In addition, the indications and contraindications of a removable partial prosthesis as well as its advantages and disadvantages are not being presented by the practitioner and to the patient. Many well fabricated removable prostheses demonstrate longevity. A conventional removable prosthesis is less invasive and thus less time consuming than an implant supported prosthesis. One of the major problems with removable prostheses is that the patient usually does not have a good oral hygiene regimen and many do not return to the clinician for periodic exams, where the need for rebasing of denture bases and occlusal changes should be evaluated. Home care by patients with any prosthetics is mandatory and should be monitored by the clinician and dental hygienist.

In addition, the clinician should be able to use removable prosthetics first as a diagnostic tool. Through the use of removable prostheses, the practitioner may be able to establish the esthetics desired with the restoration of the fully or partially edentulous arches in terms of facial height and contour including lip contours. These treatment or interim prosthesis are also used with tissue conditioners so as to reduce or eliminate soft tissue inflammation. They are used if and when ridge problems occur that require surgery, such as with an epulis, tumors, and surgical alteration of one or more of the ridges. The interim prostheses are constructed for both partially edentulous and completely edentulous situations. Usually the short term interim removable partial dentures are all acrylic with wrought buccal and lingual clasps and a soldered occlusal rest. Once the patient adapts to their newly restored vertical and horizontal dimensions and is comfortable with their facial appearance, should they ever decide to have implants, the removable prosthesis can be a guide for proper and essential implant placement. In essence, this is used for progressive implant treatment planning. Furthermore, the removable prosthesis can also serve as the first stage provisional prosthesis after implant placement.

\section{Conclusion}

This paper just touches the tip of the iceberg of the problem facing the profession. There is much more and the dental profession should continue to monitor the problems mentioned as well as/and also encourage the educational institutions responsible to consider the need to increase time allotments for teaching removable prosthodontics. This will help our profession to keep with the public's growing need for removable prosthesis. 


\section{References}

1. Warden D (2002) The dentist-laboratory relationship: a system for success. J Am Coll Dent 69: 12-4.

2. Napier B (2011) The relationship between dentists and dental laboratories-Predictions for the future. J Calif Dent Assoc 39: 569-71.

3. Christensen GJ (2002) The dental laboratory dilemma in America. J Am Coll Dent 69: 9-11.

4. Goldstein G (2008) Who does your laboratory work? Int J Prosthodont 21: 192-4.

5. Markovits S, Schnader YE, Reid PE, Federico P, Baum W (2010) A Profession in Crises. New York 195. State Dent Assoc J 76: $12-3$.

6. Douglass CW, Shih A, Ostry L (2002) Will there be a need for complete dentures in the United States in 2020. J Prosthet Dent 87: 5-8.

7. Douglass CW, Watson AJ (2002) Future needs for fixed and removable partial dentures in the United States. J Prosthet Dent 87: 9-14.

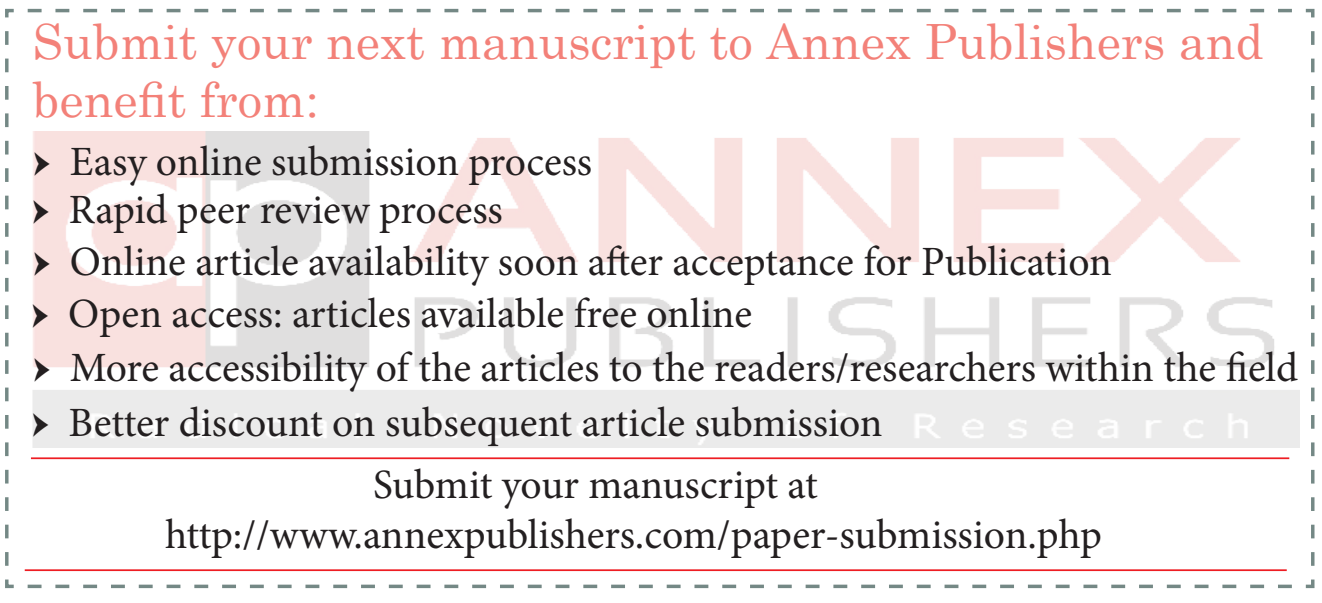

